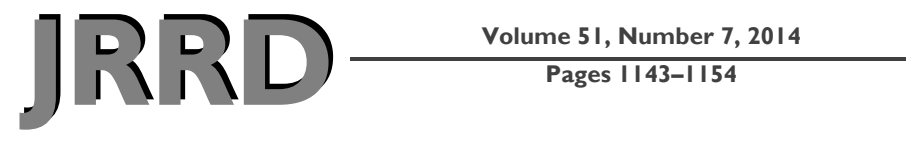

\title{
Comprehensive versus consultative rehabilitation services postacute stroke: Outcomes differ
}

\author{
Margaret G. Stineman, MD; ${ }^{1-2}$ Dawei Xie, PhD; ${ }^{1}$ Jibby E. Kurichi, MPH; ${ }^{1 *}$ Pui L. Kwong, MPH; ${ }^{1}$ W. Bruce \\ Vogel, PhD; ${ }^{3}$ Diane Cowper Ripley, PhD; ${ }^{3}$ Barbara E. Bates, MD $^{4}$ \\ ${ }^{1}$ Center for Clinical Epidemiology and Biostatistics and ${ }^{2}$ Department of Physical Medicine and Rehabilitation, Uni- \\ versity of Pennsylvania, Philadelphia, PA; ${ }^{3}$ Center of Innovation on Disability and Rehabilitation Research, Malcom \\ Randall Department of Veterans Affairs Medical Center (VAMC), Gainesville, FL; and Department of Health Out- \\ comes and Policy, University of Florida, Gainesville, FL; ${ }^{4}$ Samuel S. Stratton VAMC, Albany, NY; and Department of \\ Physical Medicine and Rehabilitation, Albany Medical College, Albany, NY
}

\begin{abstract}
Comprehensive rehabilitation services after acute stroke have been shown efficacious in European trials; however, their effectiveness in everyday practices in the United States is unknown. We compared outcomes of veteran patients provided with comprehensive rehabilitation with those provided with consultative rehabilitation services after acute stroke using propensity scores. Outcomes included change in patients' physical and cognitive independence after rehabilitation, discharge to home as opposed to other settings, and 1-yr after hospital discharge survival. Of the 2,963 patients in the study, 683 (23.1\%) received comprehensive rehabilitation while the remaining patients received consultative services. We found, after propensity adjustment, that those who received comprehensive rehabilitation compared with consultative gained on average 12.8 (95\% confidence interval [CI]: 9.1 to 16.5$)$ more points of physical independence on a 78-point scale and gained 1.5 (95\% CI: 0.8 to 2.2) more points of cognitive independence on a 30-point scale. The likelihoods of discharge to home from the hospital (odds ratio [OR] = 1.61, 95\% CI: 1.07 to 2.44 ) and 1 yr posthospital discharge survival (OR $=1.79$, 95\% CI: 1.25 to 2.56 ) were significantly higher among those who received comprehensive rehabilitation. Among patients hospitalized for acute stroke, comprehensive rehabilitation services are associated with greater recovery of physical and cognitive independence, improved home discharge likelihood, and improved 1 yr survival.
\end{abstract}

Key words: acute stroke, cognitive independence, function, home discharge, outcomes, propensity risk score, rehabilitation services, stroke, survival, veterans.

\section{INTRODUCTION}

An estimated 795,000 people in the United States experience a new or acute stroke annually, with an estimated cost of $\$ 73.7$ billion in 2010 [1]. Nearly half of those surviving 6 mo remain with neurological deficits, which can cause disabilities, reduce quality of life, burden

\footnotetext{
Abbreviations: CARF $=$ Commission on Accreditation of Rehabilitation Facilities, CI = confidence interval, FIM = Functional Independence Measure, FSOD = Functional Status Outcomes Database, GEE = general estimating equation, ICD-9$\mathrm{CM}=$ International Classification of Diseases-Ninth RevisionClinical Modification, ICU = intensive care unit, IRF = inpatient rehabilitation facility, $\mathrm{OR}=$ odds ratio, $\mathrm{PAC}=$ postacute care, $\mathrm{PM} \& \mathrm{R}=$ physical medicine and rehabilitation, $\mathrm{PTF}=$ patient treatment file, $\mathrm{SD}=$ standard deviation, $\mathrm{SRU}=$ specialized rehabilitation unit, VA = Department of Veterans Affairs, VAMC = Department of Veterans Affairs Medical Center, VHA = Veterans Health Administration.

*Address all correspondence to Jibby E. Kurichi, MPH; Department of Biostatistics and Epidemiology, Center for Clinical Epidemiology and Biostatistics, School of Medicine, University of Pennsylvania, 907 Blockley Hall, 423 Guardian Dr, Philadelphia, PA 19104-6021; 215-898-8490; fax: 215-573-2017. Email: jkurichi@mail.med.upenn.edu http://dx.doi.org/10.1682/JRRD.2014.03.0084
} 
family members, and cause premature institutionalization. Among 108 patients with acute stroke $65 \mathrm{yr}$ and older from the Framingham study, 50 percent had residual hemiparesis, 31 percent were unable to walk without assistance, 26 percent were dependent in activities of daily living, 19 percent had aphasia, and 26 percent were institutionalized at 6 mo poststroke [2].

Evidence primarily from Europe based on 41 trials involving 6,936 participants shows that interdisciplinary rehabilitation provided on an organized stroke unit compared with care on a general hospital ward leads to increased independency, less need for institutionalization, and increased survival after hospital discharge [3]. Although the benefits of comprehensive stroke unit care are clear from the European literature, the effectiveness of comprehensive services on dedicated bed sections during acute hospitalization as practiced in the United States is not well established.

Because comprehensive stroke rehabilitation supported by Medicare tends to be provided in inpatient rehabilitation facilities (IRFs) as separate postacute care (PAC) hospitalizations after acute hospital discharge, it is difficult to generalize findings of efficacy from European stroke units to U.S. rehabilitation services in IRFs. However, within the Veterans Health Administration (VHA), patients hospitalized for acute stroke are routinely assessed by interprofessional rehabilitation teams soon after hospital admission according to VHA clinical guidelines [4]. Following this assessment, some patients are transferred to specialized bed services within the acute hospitalization where they receive rehabilitation on discrete units analogous in comprehensiveness to the services provided in dedicated European stroke units. Other patients remain on nonrehabilitative hospital services where they receive consultative rehabilitation services analogous to general wards in the European studies [3]. Consequently, the VHA system provides an opportunity to study the effectiveness of rehabilitation services provided in the United States that more closely mirrors the European stroke model.

Taking advantage of the large integrated network of Department of Veterans Affairs (VA) hospitals, we compared the degree of functional recovery, home discharge versus other settings (extended care in a nursing home, discharge against medical advice, discharge to a non-VA hospital, and other), and $1 \mathrm{yr}$ survival in patients who received comprehensive stroke rehabilitation on a dedicated bed section with those who received consultative rehabilitation during their acute hospitalization. We believe our study is the first attempt in the United States to compare the effectiveness of comprehensive and consultative stroke rehabilitation provided within an integrated health system.

\section{METHODS}

\section{Setting and Patients}

Included were the 85 VA medical centers (VAMCs) accredited by the Commission on Accreditation of Rehabilitation Facilities (CARF) during the study years. CARF accreditation certifies that facilities are capable of providing patients with quality integrated inpatient rehabilitation programs and ensures that facilities provide a similar standard of rehabilitation services. To better reflect the timeline structure of the European studies, we limited analyses to veterans whose inpatient rehabilitation began and finished during their acute hospitalizations.

Patient information was obtained from eight national VHA databases used to track the health status and healthcare utilization of veterans, including the patient treatment files (PTFs) (main, bed section, procedure), two outpatient care files (visit, event), the extended care file, the Beneficiary Identification Record Locator System death file, and the Functional Status Outcomes Database (FSOD) [5-8]. Extraction methods and databases descriptions have been previously reported [9-11].

Patients with hospital discharge dates between October 1, 2006, and September 30, 2008, receiving either comprehensive or consultative rehabilitation services during their index hospitalization with a principal diagnosis of a new acute stroke were included. A stroke diagnosis was based on specific International Classification of Diseases-Ninth Revision-Clinical Modification (ICD-9-CM) codes [12] being present in either the primary diagnosis field of the patients' PTF main or one or more PTF bed section record(s) indicating that stroke was the main reason for hospitalization. Based on findings of association with the receipt of rehabilitation services, we identified six categories of stroke: occlusion, embolism, or stenosis of the cerebral arteries (434.01, 434.11, 434.91); occlusion or stenosis of the precerebral arteries (433.01, 433.11, 433.21, 433.31, 433.81, 433.91); intracerebral hemorrhage (431.xx, 432.xx); subarachnoid hemorrhage (430.xx); acute, but ill-defined, cerebral vascular disease (436.xx); and transient cerebral ischemia (435.xx), which was included only if there was additional evidence of stroke indicating either hemiplegia, hemiparesis (342.xx), or one or more of the previously mentioned stroke 
codes present in secondary diagnostic fields. Patients with evidence of a previous stroke were excluded based on stroke codes being present in the PTF, outpatient care files, extended care file, or FSOD the year preceding the index hospitalization admission date.

We included veterans admitted with a principle diagnosis of new stroke, discharged alive from their acute hospitalization within a VAMC, who received and completed either comprehensive or consultative rehabilitation during that acute "index" hospitalization. Since our intent was to focus on the effect of rehabilitation services received during the index hospitalization, our analyses were limited to patients whose inpatient rehabilitation was completed prior to that hospital discharge date. There were 3,473 patients who met these inclusion criteria; of these, 2,963 were included in the analysis because $510(14.7 \%)$ were missing initial $(n=47)$ or final $(n=$ 463) functional status scores, so the main outcome of change in those patients' physical and cognitive independence could not be defined.

\section{Patient Characteristics}

Characteristics were age, sex, marital status, and living location before hospitalization. Stroke was grouped into six mutually exclusive and exhaustive categories as described previously. If there was evidence suggesting several stroke types, coding preference was given to bleeds and central nervous system involvement over occlusive and precerebral disease. Extent of paresis was categorized as bilateral, unilateral, or none.

Functional status was expressed as motor and cognitive Functional Independence Measure (FIM) scores rated at initial assessment by physical medicine and rehabilitation (PM\&R) professionals and discharge from rehabilitation services [13]. These reliable [14] and psychometrically distinct motor (score range: 13-91) and cognitive (score range: 5-35) dimensions express severity of physical disability and cognitive or communication disability, respectively, with higher scores expressing greater independence [6].

In efforts to characterize underlying comorbidities, we recorded the presence of up to 30 comorbidities using diagnostic codes developed by Elixhauser et al. [15] and applied in other comparative studies [16]. We included ICD-9-CM procedure codes classified by the clinician authors [17]. Intensive care unit (ICU) stays and the number of bed sections where treatment occurred prior to initial rehabilitation assessment were included to assess complexity.
Functional recovery time was expressed as the number of days between the initial PM\&R assessment and discharge from comprehensive or consultative rehabilitation services when initial and final functional status were measured.

\section{Inpatient Rehabilitation Treatments}

Comprehensive and consultative rehabilitation treatment services were compared. Patients were defined as the "comprehensive" group if admitted to a specialized rehabilitation unit (SRU) bed section during the index hospitalization. Like stroke units, rehabilitation in an SRU is considered highly organized and team-based. It includes a complex package of therapies as directed by a physician specialized in rehabilitation and is provided by multiple professional disciplines including physical therapists, kinesiotherapists, occupational therapists, and orthotics specialists. SRU beds are clustered in one discrete area of the hospital. High-intensity rehabilitation therapy is provided daily with the primary hospital goal shifting to functional restoration. While structurally similar to stroke units, SRUs are mixed rehabilitation bed sections where patients are rehabilitated for a variety of medical conditions or injuries.

Patients were defined as the lower-intensity "consultative" rehabilitation treatment group if they received only consultative rehabilitation during the index hospitalization. While the same types of professionals are available as in the SRUs, consultative rehabilitation is less formally organized. Functional restoration remains a secondary rather than primary goal, and patients remain in a nonrehabilitation bed section, typically medical or neurological bed sections. Consultative therapy, ranging in frequency from two visits to several visits per week, is less intense than comprehensive. The clinical decision to provide comprehensive or consultative rehabilitation occurs after initial assessment by the rehabilitation team.

\section{Outcomes}

Our primary outcomes were changes in patients' physical and cognitive functional independence obtained by subtracting motor and cognitive FIM scores (as described previously) at the initial poststroke assessment from those obtained during the final assessment from rehabilitation services. Secondary outcomes were discharge home from the hospitalization compared with other settings and $1 \mathrm{yr}$ survival from the hospital discharge date. These four outcomes were selected because they represent commonly recommended and applied end points for stroke trials [18]. 


\section{Analyses}

Frequencies and proportions for categorical variables and mean \pm standard deviation (SD) for continuous variables were applied to compare patients who received comprehensive versus consultative rehabilitation. The relationship between receipt of comprehensive or consultative rehabilitation and patient characteristics and all outcomes was addressed applying chi-square tests and Student $t$-tests. To reduce the effects of treatment selection bias, all factors believed to potentially influence clinicians' decisions to admit the patient to an SRU were included in a logistic regression model to estimate the likelihood of receiving comprehensive versus consultative rehabilitation. Specifically, predictor variables included demographics, motor and cognitive FIM scores at initial assessment, previous living circumstances, stroke type and extent of paresis, comorbidities, number of bed sections on which treatment occurred, hospital procedures and ICU stays occurring prior to the rehabilitation treatment decision point, and time between hospital admission and initial assessment. Clinically anticipated and statistically important interactions were added. The model yielded a propensity score for each patient that reflected the probability of him or her receiving comprehensive versus consultative rehabilitation.

Patients were then distributed into five groups according to propensity score quintiles. Because it is possible that the propensity scores or quintiles could not capture all the confounding introduced by some variables, propensity score quintiles, a dichotomous treatment variable (comprehensive vs consultative), and all variables were included in a model for each of the main and secondary outcomes. Backward selection was used to remove nonsignificant variables one at a time. Then, propensity score quintiles along with the dichotomous treatment variable and any variables that remained significant independent predictors after backward selection were included in a separate general estimating equation (GEE) model (SAS Institute Inc; Cary, North Carolina) for each outcome. GEE models were used to consider the clustering effects by VAMCs.

We performed two additional analyses. In the first analysis, we added recovery time as a continuous variable to the final propensity-adjusted outcome models recognizing that longer functional recovery times expressed as the number of days between initial and final functional assessment could have benefited the comprehensive treatment group. We did not treat it as the other confounders because recovery time was not observed at the study baseline, which is the initial assessment.
The second analysis estimated the effect of rehabilitation treatment-adjusting confounders directly in multivariable models without including the propensity score. The selection of variables was hypothesis-driven based on clinical plausibility and literature review of rehabilitation referral decision-making and the determinants of functional recovery [19-27], mortality [27-32], and home discharge following hospitalization [33-40]. It is generally recommended that propensity analysis be treated as the main analysis over traditional covariate adjustment analysis [41]. If the effects remain in the same direction and remained statistically significant in the primary propensity-adjusted analysis and the two additional analyses, we assumed that findings were robust.

\section{RESULTS}

Patient age was $67.9 \pm 11.7 \mathrm{yr}$ (mean \pm SD), and 97.3 percent were male. Most patients were admitted from home (95.5\%), with small minorities being transferred from non-VA hospitals or extended care facilities. Occlusion of cerebral arteries was the most common stroke type, and hypertension, diabetes, and arrhythmias were the most frequently recorded comorbidities (Table 1), with 1.8 percent receiving mechanical ventilation. Almost 17 percent required an ICU admission (Table 1). Total hospital stay was $14.3 \pm 18.0 \mathrm{~d}$.

A total of 683 (23.1\%) patients received comprehensive rehabilitation, with the remaining patients receiving consultative rehabilitation. When compared with those who received consultative rehabilitation services, patients who had comprehensive rehabilitation at initial assessment were, on average, more physically and cognitively disabled and tended to have more comorbidities and procedures as reported previously. Time to initial comprehensive rehabilitation was $4.60 \pm 6.58 \mathrm{~d}$. Time to initial consultative rehabilitation was $1.90 \pm 3.39 \mathrm{~d}$, with 10 percent of patients hospitalized for $35 \mathrm{~d}$ or longer. Functional recovery time was $24.40 \pm 17.36 \mathrm{~d}$ for the comprehensive group compared with $6.20 \pm 11.06 \mathrm{~d}$ for those who received consultative therapy.

Table 2 shows patient outcomes by rehabilitation type. Overall motor and cognitive FIM changes were $11.49 \pm 15.20$ and $1.48 \pm 4.16$, respectively. Overall, 89.4 percent of patients were discharged to home. The remaining were discharged to a different setting, including 0.6 percent to a non-VA hospital, 8.4 percent to 
Table 1.

Characteristics of patients included in study.

\begin{tabular}{|c|c|c|c|c|}
\hline Characteristic & $\begin{array}{l}\text { All Patients } \\
(N=2,963)\end{array}$ & $\begin{array}{l}\text { Comprehensive } \\
\text { Rehabilitation } \\
(n=683,23.1 \%)\end{array}$ & $\begin{array}{c}\text { Consultative } \\
\text { Rehabilitation } \\
(n=2,280,76.9 \%)\end{array}$ & $p$-Value \\
\hline \multicolumn{5}{|l|}{ Patient-Level } \\
\hline Age, yr (mean \pm SD) & $67.9 \pm 11.65$ & $67.1 \pm 10.99$ & $68.1 \pm 11.83$ & 0.03 \\
\hline Male, $n(\%)$ & 2,883 (97.3) & $667(97.7)$ & $2,216(97.2)$ & 0.51 \\
\hline Marital Status, $n(\%)$ & & & & 0.33 \\
\hline Married & $1,263(42.6)$ & $280(41.0)$ & $983(43.1)$ & \\
\hline Living Location Before Hospitalization, $n$ (\%) & & & & 0.006 \\
\hline Extended Care & $21(0.7)$ & $3(0.4)$ & $18(0.8)$ & \\
\hline Hospital & $111(3.7)$ & $39(5.7)$ & $72(3.2)$ & \\
\hline Home & $2,831(95.5)$ & 641 (93.9) & 2,190 (96.1) & \\
\hline Intracerebral Hemorrhage & $188(6.3)$ & $53(7.8)$ & $135(5.9)$ & \\
\hline Subarachnoid Hemorrhage & $32(1.1)$ & $7(1.0)$ & $25(1.1)$ & \\
\hline Other CNS Hemorrhage & $41(1.4)$ & $9(1.3)$ & $32(1.4)$ & \\
\hline Acute, TIA, and Nonspecific & $124(4.2)$ & $29(4.2)$ & $95(4.2)$ & \\
\hline Type of Paresis, $n$ (\%) & & & & $<0.001$ \\
\hline Lateral & 2,299 (77.6) & $605(88.6)$ & $1,694(74.3)$ & \\
\hline Bilateral & $77(2.6)$ & $14(2.0)$ & $63(2.8)$ & \\
\hline None & 587 (19.8) & $64(9.4)$ & 523 (22.9) & \\
\hline Functional Status (mean \pm SD) & & & & $<0.001$ \\
\hline Chronic Blood Loss Anemia & $18(0.6)$ & $2(0.3)$ & $16(0.7)$ & 0.23 \\
\hline Chronic Pulmonary Disease & $578(19.5)$ & 129 (18.9) & 449 (19.7) & 0.64 \\
\hline Coagulopathy & $141(4.8)$ & $38(5.6)$ & $103(4.5)$ & 0.26 \\
\hline Congestive Heart Failure & $464(15.7)$ & $101(14.8)$ & 363 (15.9) & 0.47 \\
\hline Deficiency Anemias & $474(16.0)$ & $96(14.1)$ & $378(16.6)$ & 0.11 \\
\hline Depression & $580(19.6)$ & $159(23.3)$ & $421(18.5)$ & 0.005 \\
\hline Diabetes & $1,275(43.0)$ & $313(45.8)$ & $962(42.2)$ & 0.09 \\
\hline Diabetes with Chronic Complications & $480(16.2)$ & 125 (18.3) & $355(15.6)$ & 0.09 \\
\hline Drug Abuse & 257 (8.7) & $55(8.1)$ & $202(8.9)$ & 0.51 \\
\hline Fluid and Electrolyte Disorders & 383 (12.9) & $104(15.2)$ & $279(12.2)$ & 0.04 \\
\hline Hypertension & 2,599 (87.7) & $612(89.6)$ & 1,987 (87.1) & 0.09 \\
\hline Hypertension with Complication & $36(1.2)$ & $17(2.5)$ & $19(0.8)$ & 0.001 \\
\hline Hypothyroidism & $244(8.2)$ & $62(9.1)$ & $182(8.0)$ & 0.36 \\
\hline Liver Disease & $131(4.4)$ & $29(4.2)$ & $102(4.5)$ & 0.80 \\
\hline Lymphoma & $35(1.2)$ & $8(1.2)$ & $27(1.2)$ & 0.98 \\
\hline
\end{tabular}


JRRD, Volume 51, Number 7, 2014

Table 1. (cont)

Characteristics of patients included in study.

\begin{tabular}{|c|c|c|c|c|}
\hline Characteristic & $\begin{array}{l}\text { All Patients } \\
(N=2,963)\end{array}$ & $\begin{array}{c}\text { Comprehensive } \\
\text { Rehabilitation } \\
(n=683,23.1 \%)\end{array}$ & $\begin{array}{c}\text { Consultative } \\
\text { Rehabilitation } \\
(n=2,280,76.9 \%)\end{array}$ & $p$-Value \\
\hline Metastatic Cancer & $61(2.1)$ & $13(1.9)$ & $48(2.1)$ & 0.74 \\
\hline Other Neurological Disorders & $397(13.4)$ & $86(12.6)$ & $311(13.6)$ & 0.48 \\
\hline Paralysis & $80(2.7)$ & $21(3.1)$ & $59(2.6)$ & 0.49 \\
\hline Peptic Ulcer Disease with Bleeding & $73(2.5)$ & $11(1.6)$ & $62(2.7)$ & 0.10 \\
\hline Psychoses & $419(14.1)$ & $108(15.8)$ & $311(13.6)$ & 0.15 \\
\hline Pulmonary Circulation Disease & $52(1.8)$ & $15(2.2)$ & $37(1.6)$ & 0.32 \\
\hline Renal Failure & 205 (6.9) & $46(6.7)$ & $159(7.0)$ & 0.83 \\
\hline Rheumatoid Arthritis & $56(1.9)$ & $14(2.0)$ & $42(1.8)$ & 0.73 \\
\hline Solid Tumor Without Metastasis & 495 (16.7) & $96(14.1)$ & 399 (17.5) & 0.03 \\
\hline \multicolumn{5}{|l|}{$\begin{array}{l}\text { Treatment and Test Administered Prior to Initial } \\
\text { Assessment, } n(\%)\end{array}$} \\
\hline Audiology and Ophthalmologic & $2(0.1)$ & $0(0.0)$ & $2(0.1)$ & 0.44 \\
\hline Behavioral Health & $24(0.8)$ & $8(1.2)$ & $16(0.7)$ & 0.23 \\
\hline Cardiac Diagnostic Imaging & $735(24.8)$ & $202(29.6)$ & $533(23.4)$ & 0.001 \\
\hline Cardiac Surgery & $11(0.4)$ & $3(0.4)$ & $8(0.4)$ & 0.74 \\
\hline Cardiopulmonary Critical Interventions & $35(1.2)$ & $12(1.8)$ & $23(1.0)$ & 0.11 \\
\hline CNS Minimally Invasive Diagnostics & $1,384(46.7)$ & $344(50.4)$ & $1,040(45.6)$ & 0.03 \\
\hline CNS Procedures and Invasive Diagnostics & $13(0.4)$ & $3(0.4)$ & $10(0.4)$ & 0.99 \\
\hline Dental/Oral Surgery & $3(0.1)$ & $1(0.1)$ & $2(0.1)$ & 0.67 \\
\hline Renal/Genitourinary Procedures & $40(1.3)$ & $13(1.9)$ & $27(1.2)$ & 0.15 \\
\hline Renal Dialysis & $17(0.6)$ & $4(0.6)$ & $13(0.6)$ & 0.96 \\
\hline Serious Nutritional Compromise & $41(1.4)$ & $16(2.3)$ & $25(1.1)$ & 0.01 \\
\hline Swallowing Studies & $31(1.0)$ & $14(2.0)$ & $17(0.7)$ & 0.003 \\
\hline Transfusion & $49(1.7)$ & 13 (1.9) & $36(1.6)$ & 0.56 \\
\hline Wound Care & $3(0.1)$ & $1(0.1)$ & $2(0.1)$ & 0.67 \\
\hline \multicolumn{5}{|l|}{ Treatment-Related Factors } \\
\hline $\begin{array}{l}\text { No. of Hospital Service on Which Treatment } \\
\text { Occurred (mean } \pm \text { SD) }\end{array}$ & $1.3 \pm 0.66$ & $1.8 \pm 0.94$ & $1.2 \pm 0.46$ & $<0.001$ \\
\hline $\begin{array}{l}\text { Time Between Hospital Admission and Initial } \\
\text { Assessment, d (mean } \pm \text { SD) }\end{array}$ & $2.5 \pm 4.49$ & $4.6 \pm 6.58$ & $1.9 \pm 3.40$ & $<0.001$ \\
\hline $\begin{array}{l}\text { Recovery Time (length of stay in PM\&R } \\
\text { service), d (mean } \pm \text { SD) }\end{array}$ & $10.4 \pm 14.91$ & $24.4 \pm 17.36$ & $6.2 \pm 11.06$ & $<0.001$ \\
\hline ICU Admission, $n(\%)$ & $491(16.6)$ & $82(12.0)$ & 409 (17.9) & 0.001 \\
\hline
\end{tabular}


compared with consultative rehabilitation had, on average, a 12.81-point (95\% confidence interval [CI]: 9.05-16.57) greater increase in motor FIM (out of a 78-point range), a 1.51-point (95\% CI: 0.83-2.19) greater increase in cognitive FIM (out of a 30-point range), a greater likelihood of discharge home (odds ratio [OR] $=1.49 ; 95 \%$ CI: 1.04 $2.14)$, and better 1 yr survival (OR $=1.55$; 95\% CI: 1.09 2.20).

In the first additional analyses that added functional recovery time to the propensity adjustment, those who received comprehensive compared with those who received consultative rehabilitation showed similar treatment-related outcome differences.

In the second additional analyses that adjusted for confounders without estimating a propensity score, those who received comprehensive compared with those who received consultative rehabilitation were estimated as having even greater relative average increases in motor and cognitive FIM scores. The effect of comprehensive rehabilitation was marginally significant on the $1 \mathrm{yr}$ survival outcome and not significant for the home discharge outcome.

\section{DISCUSSION}

After reducing the effects of treatment-selection bias, patients who received comprehensive rehabilitation achieved a level of physical functional independence that was on average 12.81 points higher as measured by the motor FIM when compared with those who received consultative rehabilitation. Recognizing that a difference of two or more motor FIM points is considered clinically important, an incremental gain of this magnitude is clearly meaningful [42-43]. Although receipt of comprehensive compared with consultative services was significantly associated with achievement of higher cognitive functional independence, the magnitude of difference for cognitive outcomes was smaller than for physical recovery. This finding is consistent with the goals of medical rehabilitation, which is often more focused on physical than on cognitive functional recovery. Our findings of a small comparative benefit support future efforts to look more closely at the benefits of cognitive rehabilitation. To date, evidence supporting memory, language, and cognitive rehabilitation is limited [44]. Our propensityadjusted analyses also documented a survival advantage and greater odds of home discharge associated with com- prehensive rehabilitation consistent with the European studies [3], which showed improvements in the same outcomes with more comprehensive rehabilitation services.

While our two additional analyses supported robustness of observed differences in functional gains, the direct adjustment of confounders did not support a relative home discharge advantage. In the VA, rehabilitation services assist in discharge planning. In an integrated healthcare system such as the VA, similar home discharge likelihood coupled with higher functional gains among those receiving comprehensive compared with consultative rehabilitation would be expected if discharge planning is operating optimally. Such a pattern could indicate that PM\&R teams are appropriately selecting those patients for more intensive services who, due to limited caregiver support or lack of accessibility features, need to achieve higher degrees of independence in order to be discharged home.

Unlike the VHA, comprehensive rehabilitation in the private sector is typically provided after discharge from the acute hospitalization and is generally considered PAC. Nevertheless, PAC research shows improved functional recovery with admission to a specialized IRF over less intensive subacute or skilled nursing facilities [43,45-49].

As in our study, literature support of more comprehensive rehabilitation services improving home discharge likelihood over consultative services is not consistent. While the majority of studies document relative benefits in VAMCs [50] and private sector facilities [48-49], comprehensive rehabilitation in an IRF compared with a subacute rehabilitation unit in one study was associated with similar proportions of people being discharged to the community [45]. Home discharge can be influenced by factors outside the direct control of hospitalists, such as home accessibility and the availability of caregivers.

This study has a number of limitations. Potentially unmeasured confounding related to real world selection of comprehensive rehabilitation could be inflating the treatment-related outcome differences shown. Nevertheless, consistency of findings across our large observational study with the European studies [3] support the effectiveness of real-world comprehensive rehabilitation services for stroke. Because the VHA populations are primarily male and because of structural differences in the provision of rehabilitation, we cannot be certain that findings will generalize to rehabilitation services provided to the larger U.S. population. 


\section{CONCLUSIONS}

These findings have implications to the care of patients with stroke in both the VHA and Medicare-reimbursed settings. Movement to bundled payments appears to be accelerating in response to passage of the Patient Protection and Affordable Care Act in 2010 [47]. The "minimal essential coverage" for tens of millions of patients in Medicare will include entitlement for rehabilitation services. Details about what constitutes "rehabilitation" are unclear. Cost containment efforts by necessity will move toward less comprehensive rehabilitation. It is thus essential to identify those conditions where comparative evidence supports comprehensive rehabilitation. Evidence is growing for stroke. As for effective models of care, it is noteworthy that VHA and Canadian best practice standards for stroke recognize the importance of standard functional assessment and rehabilitative potential evaluation early during hospitalization [51-52].

\section{ACKNOWLEDGMENTS}

\author{
Author Contributions: \\ Study concept and design: M. G. Stineman, D. Xie, P. L. Kwong. \\ Analysis and interpretation of data: P. L. Kwong, D. Xie, M. G. Stineman, \\ J. E. Kurichi, W. B. Vogel. \\ Drafting of manuscript: M. G. Stineman. \\ Critical revision of manuscript for important intellectual content: \\ J. E. Kurichi, B. E. Bates, P. L. Kwong, D. Xie, D. Cowper Ripley, \\ W. B. Vogel. \\ Obtained funding: M. G. Stineman, J. E. Kurichi. \\ Administrative, technical, or material support: J. E. Kurichi.
}

Financial Disclosures: The authors have declared that no competing interests exist.

Funding/Support: This material was based on work supported by the Agency for Healthcare Research and Quality (grant R01HS018540).

It is also supported by resources and the use of facilities at the University of Pennsylvania, Philadelphia, Pennsylvania; the Samuel S. Stratton VAMC, Albany, New York; and the North Florida/South Georgia VA Health System, Gainesville, Florida.

Additional Contributions: We would like to thank Xinping Wang, $\mathrm{PhD}$, for acquisition of the data.

Institutional Review: This longitudinal cohort study was approved by the institutional review boards at the University of Pennsylvania, Philadelphia, Pennsylvania; the Samuel S. Stratton VAMC, Albany, New York; the University of Florida, Gainesville, Florida; and the VA Research and Development Committees in Albany and Gainesville.

Participant Follow-Up: The authors have no plans to notify the study subjects of the publication of this article because of a lack of contact information.

Disclaimer: The views expressed in this article are those of the authors and should not be interpreted as those of the sponsor or any other orga- nization. The content is solely the responsibility of the authors and does not necessarily represent the official views of the Agency for Healthcare Research and Quality. The Agency for Healthcare Research and Quality played no role in the design or conduct of the study; in the analysis and interpretation of the data; or in the preparation, review, or approval of the manuscript.

\section{REFERENCES}

1. American Heart Association; American Stroke Association. Impact of stroke (Stroke statistics) [Internet]. Dallas (TX): American Stroke Association; 2013 [updated 2014 May 27; cited 2013 July 11]. Available from: http://www.strokeassociation.org/STROKEORG/AboutStroke/ Impact-of-Stroke-Stroke-statistics UCM 310728 Article.jsp

2. Kelly-Hayes M, Beiser A, Kase CS, Scaramucci A, D'Agostino RB, Wolf PA. The influence of gender and age on disability following ischemic stroke: The Framingham study. J Stroke Cerebrovasc Dis. 2003;12(3):119-26. [PMID:17903915] http://dx.doi.org/10.1016/S1052-3057(03)00042-9

3. Stroke Unit Trialists' Collaboration. Organised inpatient (stroke unit) care for stroke. Cochrane Database Syst Rev. 2007;(4):CD000197. [PMID:17943737] http://dx.doi.org/10.1002/14651858.CD000197.pub2

4. Management of Stroke Rehabilitation Working Group. VA/ DOD Clinical practice guideline for the management of stroke rehabilitation. J Rehabil Res Dev. 2010;47(9):1-43. [PMID:21213454]

5. Kubal JD, Webber S, Cooper DC, Waight S, Hynes DM. A primer on US mortality databases used in health services research. VIReC Insights. Vol. 5. Hines (IL): Veterans Affairs Information Resource Center; 2000.

6. Stineman MG, Shea JA, Jette A, Tassoni CJ, Ottenbacher KJ, Fiedler R, Granger CV. The Functional Independence Measure: Tests of scaling assumptions, structure, and reliability across 20 diverse impairment categories. Arch Phys Med Rehabil. 1996;77(11):1101-8. [PMID:8931518] http://dx.doi.org/10.1016/S0003-9993(96)90130-6

7. VHA Office of Information. VHA corporate databases monograph. Washington (DC): Department of Veterans Affairs; 2007.

8. VIReC Research User Guide. VHA medical SAS inpatient datasets FY2006. Hines (IL): VA Information Resource Center; 2007.

9. Bates B, Stineman MG, Reker DM, Kurichi JE, Kwong PL. Risk factors associated with mortality in veteran population following transtibial or transfemoral amputation. J Rehabil Res Dev. 2006;43(7):917-28. [PMID:17436177] http://dx.doi.org/10.1682/JRRD.2006.03.0030

10. Kurichi JE, Kwong PL, Reker DM, Bates BE, Marshall CR, Stineman MG. Clinical factors associated with prescription 
of a prosthetic limb in elderly veterans. J Am Geriatr Soc. 2007;55(6):900-906. [PMID:17537091]

http://dx.doi.org/10.1111/j.1532-5415.2007.01187.x

11. Kurichi JE, Stineman MG, Kwong PL, Bates BE, Reker DM. Assessing and using comorbidity measures in elderly veterans with lower extremity amputations. Gerontology. 2007;53(5):255-59. [PMID:17435390]

http://dx.doi.org/10.1159/000101703

12. Reker DM, Hamilton BB, Duncan PW, Yeh SC, Rosen A. Stroke: Who's counting what? J Rehabil Res Dev. 2001; 38(2):281-89. [PMID:11392661]

13. Granger CV, Hamilton BB, Forer S. Development of a Uniform National Data System for Medical Rehabilitation. Arch Phys Med Rehabil. 1985;66(8):538-39.

14. Hamilton BB, Laughlin JA, Fiedler RC, Granger CV. Interrater reliability of the 7-level functional independence measure (FIM). Scand J Rehabil Med. 1994;26(3):115-19. [PMID:7801060]

15. Elixhauser A, Steiner C, Harris DR, Coffey RM. Comorbidity measures for use with administrative data. Med Care. 1998;36(1):8-27. [PMID:9431328] http://dx.doi.org/10.1097/00005650-199801000-00004

16. Lindenauer PK, Pekow PS, Lahti MC, Lee Y, Benjamin EM, Rothberg MB. Association of corticosteroid dose and route of administration with risk of treatment failure in acute exacerbation of chronic obstructive pulmonary disease. JAMA. 2010;303(23):2359-67. [PMID:20551406] http://dx.doi.org/10.1001/jama.2010.796

17. Bates BE, Xie D, Kwong PL, Kurichi JE, Ripley DC, Stineman MG. One-year all-cause mortality following stroke: A prediction model. PM R. 2013;6(6):473-83. http://dx.doi.org/10.1016/j.pmrj.2013.08.051

18. Sulter G, Steen C, De Keyser J. Use of the Barthel index and modified Rankin scale in acute stroke trials. Stroke. 1999;30(8):1538-41. [PMID:10436097] http://dx.doi.org/10.1161/01.STR.30.8.1538

19. Covinsky KE, Hilton J, Lindquist K, Dudley RA. Development and validation of an index to predict activity of daily living dependence in community-dwelling elders. Med Care. 2006;44(2):149-57. [PMID:16434914] http://dx.doi.org/10.1097/01.mlr.0000196955.99704.64

20. Kwakkel G, Kollen B, Twisk J. Impact of time on improvement of outcome after stroke. Stroke. 2006;37(9):2348-53. [PMID:16931787] http://dx.doi.org/10.1161/01.STR.0000238594.91938.1e

21. Ng YS, Stein J, Salles SS, Black-Schaffer RM. Clinical characteristics and rehabilitation outcomes of patients with posterior cerebral artery stroke. Arch Phys Med Rehabil. 2005;86(11):2138-43. [PMID:16271561] http://dx.doi.org/10.1016/j.apmr.2005.07.289

22. Reid JM, Gubitz GJ, Dai D, Kydd D, Eskes G, Reidy Y, Christian C, Counsell CE, Dennis M, Phillips SJ. Predict- ing functional outcome after stroke by modelling baseline clinical and CT variables. Age Ageing. 2010;39(3):360-66. [PMID:20233732]

http://dx.doi.org/10.1093/ageing/afq027

23. Schiemanck SK, Kwakkel G, Post MW, Kappelle LJ, Prevo AJ. Predicting long-term independency in activities of daily living after middle cerebral artery stroke: Does information from MRI have added predictive value compared with clinical information? Stroke. 2006;37(4):1050-54. [PMID:16497980] http://dx.doi.org/10.1161/01.STR.0000206462.09410.6f

24. Stineman MG, Zhang G, Kurichi JE, Zhang Z, Streim JE, Pan Q, Xie D. Prognosis for functional deterioration and functional improvement in late life among communitydwelling persons. PM R. 2013;5(5):360-71.

[PMID:23454447]

http://dx.doi.org/10.1016/j.pmrj.2013.02.008

25. Stineman MG, Xie D, Pan Q, Kurichi JE, Zhang Z, Saliba D, Henry-Sánchez JT, Streim J. All-cause 1-, 5-, and 10year mortality in elderly people according to activities of daily living stage. J Am Geriatr Soc. 2012;60(3):485-92. [PMID:22352414] http://dx.doi.org/10.1111/j.1532-5415.2011.03867.x

26. van de Port IG, Kwakkel G, Schepers VP, Lindeman E. Predicting mobility outcome one year after stroke: A prospective cohort study. J Rehabil Med. 2006;38(4):218-23. [PMID:16801203] http://dx.doi.org/10.1080/16501970600582930

27. Walter LC, Brand RJ, Counsell SR, Palmer RM, Landefeld CS, Fortinsky RH, Covinsky KE. Development and validation of a prognostic index for 1-year mortality in older adults after hospitalization. JAMA. 2001;285(23):2987-94. [PMID:11410097] http://dx.doi.org/10.1001/jama.285.23.2987

28. Appelros P, Nydevik I, Viitanen M. Poor outcome after first-ever stroke: Predictors for death, dependency, and recurrent stroke within the first year. Stroke. 2003;34(1): 122-26. [PMID:12511762] http://dx.doi.org/10.1161/01.STR.0000047852.05842.3C

29. Teno JM, Harrell FE Jr, Knaus W, Phillips RS, Wu AW, Connors A Jr, Wenger NS, Wagner D, Galanos A, Desbiens NA, Lynn J. Prediction of survival for older hospitalized patients: The HELP survival model. Hospitalized Elderly Longitudinal Project. J Am Geriatr Soc. 2000;48(5 Suppl):S16-24. [PMID:10809452]

30. Wang Y, Lim LL, Heller RF, Fisher J, Levi CR. A prediction model of 1-year mortality for acute ischemic stroke patients. Arch Phys Med Rehabil. 2003;84(7):1006-11. [PMID:12881825] http://dx.doi.org/10.1016/S0003-9993(03)00032-7

31. Fonarow GC, Pan W, Saver JL, Smith EE, Reeves MJ, Broderick JP, Kleindorfer DO, Sacco RL, Olson DM, 
Hernandez AF, Peterson ED, Schwamm LH. Comparison of 30-day mortality models for profiling hospital performance in acute ischemic stroke with vs without adjustment for stroke severity. JAMA. 2012;308(3):257-64.

[PMID:22797643]

http://dx.doi.org/10.1001/jama.2012.7870

32. Counsell C, Dennis M, McDowall M, Warlow C. Predicting outcome after acute and subacute stroke: Development and validation of new prognostic models. Stroke. 2002; 33(4):1041-47. [PMID:11935058]

http://dx.doi.org/10.1161/hs0402.105909

33. Andel R, Hyer K, Slack A. Risk factors for nursing home placement in older adults with and without dementia. J Aging Health. 2007;19(2):213-28. [PMID:17413132] http://dx.doi.org/10.1177/0898264307299359

34. Frank M, Conzelmann M, Engelter S. Prediction of discharge destination after neurological rehabilitation in stroke patients. Eur Neurol. 2010;63(4):227-33. [PMID:20215754] http://dx.doi.org/10.1159/000279491

35. Gordon HS, Rosenthal GE. Impact of marital status on outcomes in hospitalized patients. Evidence from an academic medical center. Arch Intern Med. 1995;155(22):2465-71. [PMID:7503606] http://dx.doi.org/10.1001/archinte.1995.00430220129014

36. Hagino T, Ochiai S, Sato E, Watanabe Y, Senga S, Haro H. Prognostic prediction in patients with hip fracture: Risk factors predicting difficulties with discharge to own home. J Orthop Traumatol. 2011;12(2):77-80. [PMID:21541772] http://dx.doi.org/10.1007/s10195-011-0138-y

37. Kurichi JE, Ripley DC, Xie D, Kwong PL, Bates BE, Stineman MG. Factors associated with home discharge after rehabilitation among male veterans with lower extremity amputation. PM R. 2013;5(5):408-17.

[PMID:23159239]

http://dx.doi.org/10.1016/j.pmrj.2012.09.578

38. Nelson MM, Smith MA, Martinson BC, Kind A, Luepker RV. Declining patient functioning and caregiver burden/ health: The Minnesota stroke survey-quality of life after stroke study. Gerontologist. 2008;48(5):573-83. [PMID:18981274] http://dx.doi.org/10.1093/geront/48.5.573

39. Nguyen TA, Page A, Aggarwal A, Henke P. Social determinants of discharge destination for patients after stroke with low admission FIM instrument scores. Arch Phys Med Rehabil. 2007;88(6):740-44. [PMID:17532895] http://dx.doi.org/10.1016/j.apmr.2007.03.011

40. Pattakos G, Johnston DR, Houghtaling PL, Nowicki ER, Blackstone EH. Preoperative prediction of non-home discharge: A strategy to reduce resource use after cardiac surgery. J Am Coll Surg. 2012;214(2):140-47.

[PMID:22265219]

http://dx.doi.org/10.1016/j.jamcollsurg.2011.11.003
41. D’Agostino RB Jr. Propensity score methods for bias reduction in the comparison of a treatment to a non-randomized control group. Stat Med. 1998;17(19):2265-81.

[PMID:9802183]

42. Deutsch AF. Outcomes and reimbursement of inpatient rehabilitation services for Medicare beneficiaries with stroke and hip fracture [thesis]. [Buffalo (NY)]: State University of New York at Buffalo; 2003.

43. Deutsch A, Granger CV, Heinemann AW, Fiedler RC, DeJong G, Kane RL, Ottenbacher KJ, Naughton JP, Trevisan M. Poststroke rehabilitation: Outcomes and reimbursement of inpatient rehabilitation facilities and subacute rehabilitation programs. Stroke. 2006;37(6):1477-82.

[PMID:16627797] http://dx.doi.org/10.1161/01.STR.0000221172.99375.5a

44. Langhorne P, Bernhardt J, Kwakkel G. Stroke rehabilitation. Lancet. 2011;377(9778):1693-1702. [PMID:21571152] http://dx.doi.org/10.1016/S0140-6736(11)60325-5

45. Kane K, Andary MT, Turk M, Goldberg G. Cost-effectiveness in stroke rehab. Arch Phys Med Rehabil. 1996;77(5):521, author reply 522-23. [PMID:8629933] http://dx.doi.org/10.1016/S0003-9993(96)90045-3

46. U.S. Department of Health and Human Services Centers for Medicare \& Medicaid Services. Report to Congress: Post acute care payment reform demonstration (PAC-PRD) [Internet]. Baltimore (MD): Centers for Medicare \& Medicaid Services; 2012 Jan [cited 2013 May 9]. Available from: http://www.cms.gov/Research-Statistics-Data-and-Systems/ Statistics-Trends-and-Reports/Reports/downloads/ Flood_PACPRD_RTC_CMS_Report_Jan_2012.pdf

47. Chan L, Sandel ME, Jette AM, Appelman J, Brandt DE, Cheng P, Teselle M, Delmonico R, Terdiman JF, Rasch EK. Does postacute care site matter? A longitudinal study assessing functional recovery after a stroke. Arch Phys Med Rehabil. 2013;94(4):622-29. [PMID:23124133] http://dx.doi.org/10.1016/j.apmr.2012.09.033

48. Kramer AM, Steiner JF, Schlenker RE, Eilertsen TB, Hrincevich CA, Tropea DA, Ahmad LA, Eckhoff DG. Outcomes and costs after hip fracture and stroke. A comparison of rehabilitation settings. JAMA. 1997;277(5):396-404.

[PMID:9010172]

http://dx.doi.org/10.1001/jama.1997.03540290048031

49. Buntin MB, Colla CH, Deb P, Sood N, Escarce JJ. Medicare spending and outcomes after postacute care for stroke and hip fracture. Med Care. 2010;48(9):776-84.

[PMID:20706167]

http://dx.doi.org/10.1097/MLR.0b013e3181e359df

50. Hoenig H, Sloane R, Horner RD, Zolkewitz M, Reker D. Differences in rehabilitation services and outcomes among stroke patients cared for in veterans hospitals. Health Serv Res. 2001;35(6):1293-1318. [PMID:11221820] 
51. Quinn TJ, Paolucci S, Sunnerhagen KS, Sivenius J, Walker MF, Toni D, Lees KR; European Stroke Organisation (ESO) Executive Committee; ESO Writing Committee. Evidencebased stroke rehabilitation: An expanded guidance document from the european stroke organisation (ESO) guidelines for management of ischaemic stroke and transient ischaemic attack 2008. J Rehabil Med. 2009; 41(2):99-111. [PMID:19225703]

http://dx.doi.org/10.2340/16501977-0301

52. Bates B, Choi JY, Duncan PW, Glasberg JJ, Graham GD, Katz RC, Lamberty K, Reker D, Zorowitz R; US Department of Defense; Department of Veterans Affairs. Veterans Affairs/Department of Defense Clinical Practice Guideline for the Management of Adult Stroke Rehabilitation Care: Executive summary. Stroke. 2005;36(9):2049-56. [PMID:16120847]

http://dx.doi.org/10.1161/01.STR.0000180432.73724.AD
Submitted for publication March 24, 2014. Accepted in revised form April 24, 2014.

This article and any supplementary material should be cited as follows:

Stineman MG, Xei D, Kurichi JE, Kwong PL, Vogel WB, Cowper Ripley D, Bates BE. Comprehensive versus consultative rehabilitation services postacute stroke: Outcomes differ. J Rehabil Res Dev. 2014;51(7):1143-54. http://dx.doi.org/10.1682/JRRD.2014.03.0084

ResearcherID/ORCID: Jibby E. Kurichi, MPH: 0000-00018694-355X; Barbara E. Bates, MD: 0000-0001-8077-2745

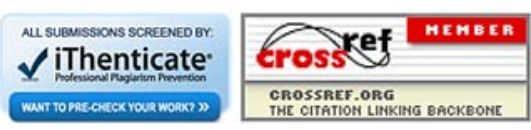

